\title{
EFFECTS OF ARMY ANT QUEENS ON LONGEVITY OF THEIR WORKERS (FORMICIDAE: DORYLINAE) ${ }^{1}$
}

\author{
By Julian F. Watkins II $^{2}$ and Carl W. Rettenmeyer ${ }^{3}$
}

Many species of ants can be kept readily for months or years in laboratory nests in which survival and colony growth are probably greater than that in the ants' natural environment. If worker ants are kept without their queen(s), survival of adult ants sometimes does not appear to be greatly decreased. For example, we have kept Camponotus pennsylvanicus (DeGeer), Pogonomyrmex occidentalis (Cresson), and P. barbatus (F. Smith) in laboratory nests without queens for 10 to 20 months. Although some of the workers often lay eggs, the colony gradually dies out. Skaife (I96I: I4I) determined the longevity of Iridomyrmex humilis Mayr by keeping about 3,500 workers in a nest without brood or queen. Half the workers died in ten months, and all were dead in 15 months. However, if the results of our experiments are applicable to other ants, isolating ants from their queens will greatly reduce survival.

There is evidence that queen ants influence the development or survival of a brood, but we have been unable to find data regarding the survival of adult workers. Brian and Hibble (1963) reported that Myrmica queen heads crushed in ethanol suppressed, and mandibular glands in paraffin oil stimulated, the growth of brood. Brian (1957) and Brian and Carr (1960) found that queens of Myrmica scabrinodis and $M$. rubra increased early larval growth, caused a smaller pupal size, improved survival of the brood, and diminished the production of gynes. Carr (1962) reported that dead queens of Myrmica also produced a measurable effect on the growth of larvae.

Army ants are among the most difficult ants to keep alive in lab-

\footnotetext{
${ }^{1}$ Contribution No. 936, Department of Entomology, Kansas Agricultural Experiment Station, Kansas State University, Manhattan, 66502. Supported by National Science Foundation Grant GB-52 and Kansas Agricultural Experiment Station Project 603. Manuscript received by the editor Sept. 25, 1967.

${ }^{2}$ Former National Defense Education Act Fellow, Kansas State University; now Assistant Professor, Department of Biology, Baylor University, Waco, Texas 76703.

${ }^{3}$ Associate Professor, Department of Entomology, Kansas State University, Manhattan.
} 
oratory nests. Colony samples with a queen and brood often can be kept for several months, but most of the brood is eaten; usually no further eggs are laid. We have seen no sign of eggs laid by workers in nests without queens. We had one queen of Neivamyrmex nigrescens become physogastric in the laboratory and lay eggs. Some of these developed into adult workers, but the size of the brood was much smaller than broods found in the field. Since workers with queens seemed to live longer than those without queens, we did the following experiment.

LONGEVITY OF WORKERS HOUSED WITH AND WITHOUT QUEENS

One thousand workers from the same colony of Neivamyrmex carolinensis (Emery) were placed in each of eight laboratory nests. One queen from the same colony having multiple functional queens was also placed in each of four of these nests. Ants in each nest were fed daily the same number of live German cockroaches (Blatella germanica) and ant larvae (Crematogaster sp.). No brood appeared in any nest. The numbers of live workers were counted after 30 days (Table I). The queens remained alive and active throughout the test. The mean survival with a queen was $78 \%$ higher than the survival without a queen.

Table 1. Effects of queens on the longevity of workers of $N$. carolinensis.

\begin{tabular}{|c|c|c|c|}
\hline \multicolumn{4}{|c|}{ No. live workers after 30 days } \\
\hline Replica & $\begin{array}{c}\text { Queen and } \\
\text { workers }\end{array}$ & $\begin{array}{c}\text { Workers } \\
\text { only }\end{array}$ & Probability \\
\hline 1 & 466 & 27 & $<0.005$ \\
\hline 2 & 629 & 462 & 0.005 \\
\hline 3 & 627 & 296 & 0.005 \\
\hline 4 & 623 & 531 & 0.010 \\
\hline Means & 586 & 329 & $<0.005$ \\
\hline
\end{tabular}

In a similar experiment, 2,00O workers of Neivamyrmex carolinensis were placed in each of four laboratory nests, and three queens from the same colony were put in each of two nests. At the end of 30 days, all workers in nests without queens were dead, but more than $50 \%$ of the workers and two of the three queens in the other nests were alive.

ATTRACTION OF WORKERS HOUSED WITH AND WITHOUT

QUEENS TO QUEEN SECRETIONS

After army ant queens have stood on a paper surface, workers from their colony will be attracted to the paper (Schneirla, I953; Watkins and Cole, I966). Watkins and Cole showed that workers 
were more attracted to secretions of pheromones deposited by their own queens than to those of conspecific queens from other colonies. They also reported that workers of Neivamyrmex nigrescens (Cresson), N. opacithorax (Emery), and N.pilosus (F. Smith) that had been kept in laboratory nests without queens for at least 25 days were more attracted to queen secretions than were workers housed with queens.

The comparative attraction of workers of $N$. carolinensis housed in laboratory nests with and without queens was tested using methods similar to those described by Watkins and Cole ( I966), except all I 5 untreated squares of a I6-square grid were used as controls rather than a single untreated square. More than four times as many workers, housed without a queen for I6 days, were attracted to the queen-square compared with the number of workers attracted when kept with a queen (Table 2).

Table 2. Attraction of workers of $N$. carolinensis from the laboratory nests with and without queens to conspecific queen secretions.

\begin{tabular}{ccccc}
\hline \hline Trials & $\begin{array}{c}\text { Days } \\
\text { without }\end{array}$ & \multicolumn{2}{c}{ Total ants on squares } & $\begin{array}{c}\text { Prob. } \\
\text { o }\end{array}$ \\
\cline { 2 - 5 } & o-sq. & u-sqs. & $<0.001$ \\
\hline 1 & 16 & 81 & 36 & $<0.001$ \\
2 & 0 & 45 & 10 & $<0.001$ \\
3 & 16 & 124 & 33 & $>0.70$ \\
4 & 0 & 1 & 11 & $<0.001$ \\
5 & 16 & 105 & 81 &
\end{tabular}

Means: workers without queen attracted to queen square, 103. workers with queen attracted to queen square, 23.

Probability of means: $<0.001$.

$q$-sq. $=1$ square on which queen had been placed.

u-sqs. $=15$ untreated squares.

\section{LICKING OF QUEENS BY WORKER ANTS}

Army ant queens probably are licked more frequently than queens of other species of ants. The extent of such licking under conditions approximating a natural bivouac is difficult to observe directly because the queens often are covered by dense masses of workers. Schneirla (1944) reported that worker army ants licked the intersegmental membranes, hypogynium, and vaginal regions of physogastric queens. Rettenmeyer (1963: 350-352) showed that workers were much more attracted to the gaster of their queen than to her head or thorax, but there was no consistent preference for any part of the gaster. 
Five physogastric queens and approximately 5,000 workers of $N$. carolinensis from the same colony were observed in laboratory nests to determine which areas of the queens' bodies were licked most often. The numbers of workers licking each queen's mouthparts, head, alitrunk, legs, petiole, and gastric segments I, 2, 3, 4, and 5 were counted every I 5 minutes for five hours (Table 3 ).

Table 3. Areas on live queens of $N$. carolinensis licked by their workers.

\begin{tabular}{|c|c|c|c|c|c|c|c|c|c|c|c|}
\hline \multirow{3}{*}{$\begin{array}{l}\text { No. } \\
\text { obser- } \\
\text { vations }\end{array}$} & \multicolumn{11}{|c|}{ Mean number of workers licking queens } \\
\hline & \multirow[b]{2}{*}{ MP } & \multirow[b]{2}{*}{$\mathrm{H}$} & \multirow[b]{2}{*}{ A } & \multirow[b]{2}{*}{$\mathrm{P}$} & \multirow[b]{2}{*}{$\mathrm{L}$} & \multicolumn{4}{|c|}{ Gastric segments } & \multirow[b]{2}{*}{5} & \multirow[b]{2}{*}{ Total } \\
\hline & & & & & & 1 & 2 & 3 & 4 & & \\
\hline 20 & 0 & .25 & .55 & .05 & .15 & .20 & 1.00 & .60 & .95 & 1.60 & 5.35 \\
\hline 19 & .16 & .11 & .42 & .05 & .16 & .47 & .79 & .53 & 1.11 & 1.78 & 5.59 \\
\hline 20 & 0 & .10 & .45 & .10 & .25 & .25 & .60 & .55 & 1.20 & 2.60 & 6.10 \\
\hline 19 & 0 & .53 & .42 & 0 & .11 & .11 & .47 & .47 & .84 & .95 & 3.90 \\
\hline 20 & .20 & .50 & .70 & .10 & .15 & .25 & 1.10 & 1.55 & 1.70 & 2.00 & 8.25 \\
\hline Total & .36 & 1.49 & 2.54 & .30 & .82 & 1.28 & 3.96 & 3.70 & 5.80 & 8.93 & 29.19 \\
\hline
\end{tabular}

$\mathrm{MP}=$ mouthparts $\mathrm{H}=$ head $\mathrm{A}=$ alitrunk $\mathrm{P}=$ petiole $; \mathrm{L}=$ legs.

In 98 observations of the five queens, workers licked all areas of the queens' bodies but consistently licked the fifth gastric segment most frequently. Based on means of all observations, the areas licked in decreasing frequency were: fifth, fourth, second, and third gastric segments; alitrunk; head; first gastric segment; legs; mouthparts; and petiole.

Hagan (1954) reported two pairs of glandular cell masses were arranged in the vicinity of the vulva of queens of Eciton hamatum. These masses have ductules extending through the exoskeleton. The physogastric condition of the queens or the presence of such glands may be responsible for the licking being concentrated on the last two gastric segments.

\section{SUMMARY AND DISCUSSION}

Worker army ants live for a longer time in the presence of their queen(s), most likely because secretions are licked from the body of the queen. The workers must carry and transmit the effect of their queen because each worker cannot lick the queen frequently. As Brian and Carr ( 1960) reported for Myrmica, the effects of the queen do not persist with the workers but the queen's presence is essential. It is unlikely in these experiments that eating of brood increased worker survival. It is also possible that the presence of a queen modifies the amount of worker activity, but no quantitative 
data on this are available. Workers were not seen to feed the queen, so probably mandibular or other secretions from the head of the queen are not involved in this longevity factor. If mouth-to-mouth trophallaxis occurred only at night, we would not have detected it.

Workers of Neivamyrmex carolinensis also became more attracted to chemicals deposited on paper by their queen after the ants had been kept in laboratory nests without queens for $\mathrm{I} 6$ days. When a queen is removed from an army ant colony in the field, the workers usually start "backtracking" or running along previous emigration and raid trails of the colony. Since more workers are attracted to the queen substance after they have been deprived of it for a number of days, this would be a mechanism for increasing the number of workers running along the backtracking columns. The ability of the workers to detect where a queen has stood suggests that they may be able to distinguish chemical trails along which a queen has run. Field observations in Panama with Eciton colonies from which queens have been removed showed that the workers primarily run along previous emigration trails but run to a lesser extent on raid trails never used by queens. Backtracking and the ability of the workers to detect traces of a queen clearly are adaptations for colony survival. If a queen is lost by falling from an emigration route, these mechanisms increase the chances that the workers will find their queen. Colonies which do not have queens either die or combine with another colony (Rettenmeyer, 1963:309). A colony is unable to replace a queen that dies, except under the unusual condition where young queens are already developing within it. The ability to detect traces of a queen along trails of other colonies may provide the stimulus for colony fusion.

\section{Literature Cited}

BRIAN, M. V.

1958. The evolution of queen control in the social Hymenoptera. Proc. 10th Int. Congr. Entomol. 2: 497-502.

Brian, M. V., and C. A. H. Carr.

1960. The influence of the queen on brood rearing in ants of the genus Myrmica. J. Ins. Physiol. 5: 81-94.

Brian, M. V., and J. Hibble.

1963. 9-oxodec-trans-2-enoic acid and Myrmica queen extracts tested for influence on brood in Myrmica. J. Ins. Physiol. 9: 25-34.

CARr, C. A. H.

1962. Further studies on the influence of the queen in ants of the genus Myrmica. Insectes Sociaux 9: 197-211. 
HaGaN, H. R.

1954. The reproductive system of the army ant queen, Eciton (Eciton) Part 2. Histology. Amer. Mus. Novit. No. 1664: 1-17.

RETTENMEYER, C. W.

1963. Behavioral studies of army ants. Univ. Kansas Sci. Bull. 44 : 281-465.

SchNeirla, T. C.

1944. The reproductive functions of the army ant queen as pace-makers of the group behavior pattern. J. New York Entomol. Soc. 52: 153-192.

Schneirla, T. C.

1953. The army-ant queen: keystone in a social system. Bull. Union Int. Etude Ins. Sociaux 1(3): 29-41.

SKAIFE, S. H.

1961. The study of ants. London: Longmans, Green. vi +178 p.

Watkins, J. F. II, And T. W. Cole.

1966. The attraction of army ant workers to secretions of their queens. Texas J. Sci. $18: 254-265$.

WHEELER, W. M.

1910. Ants: their structure, development and behavior. New York: Columbia Univ. Press. xxv +663 p. 


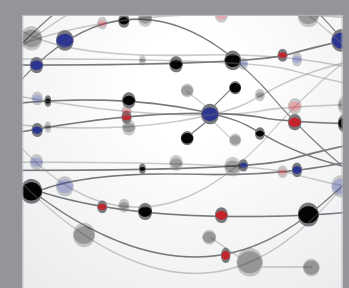

The Scientific World Journal
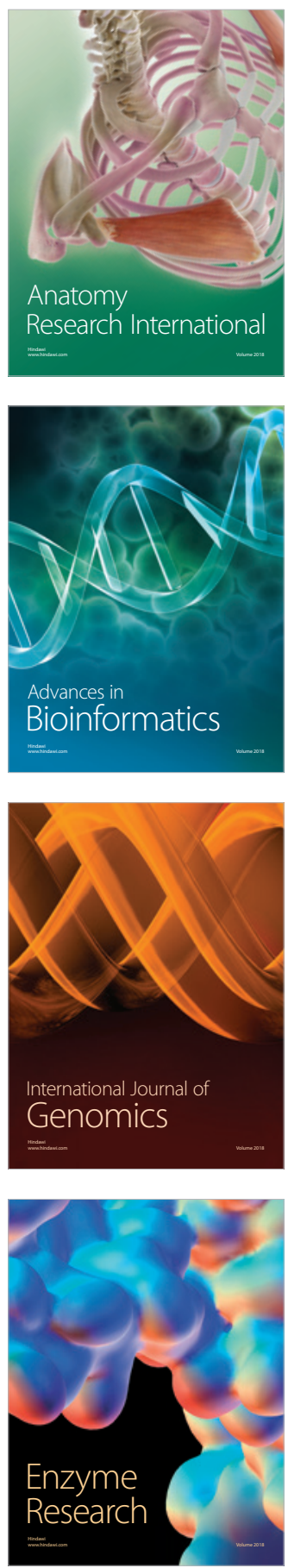
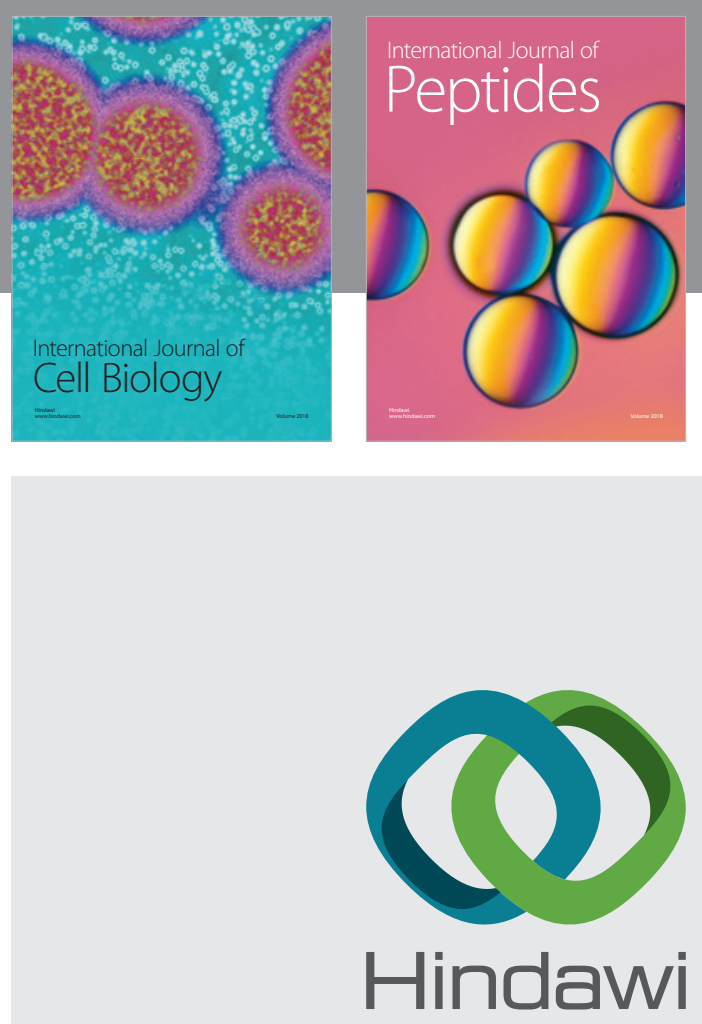

Submit your manuscripts at

www.hindawi.com
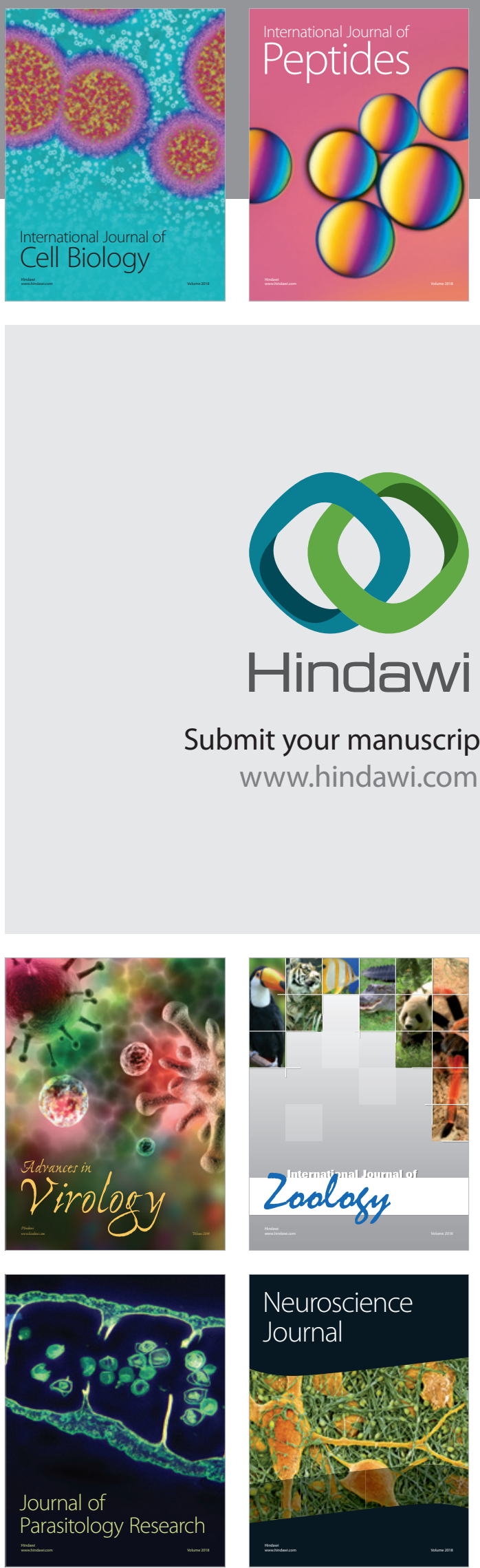
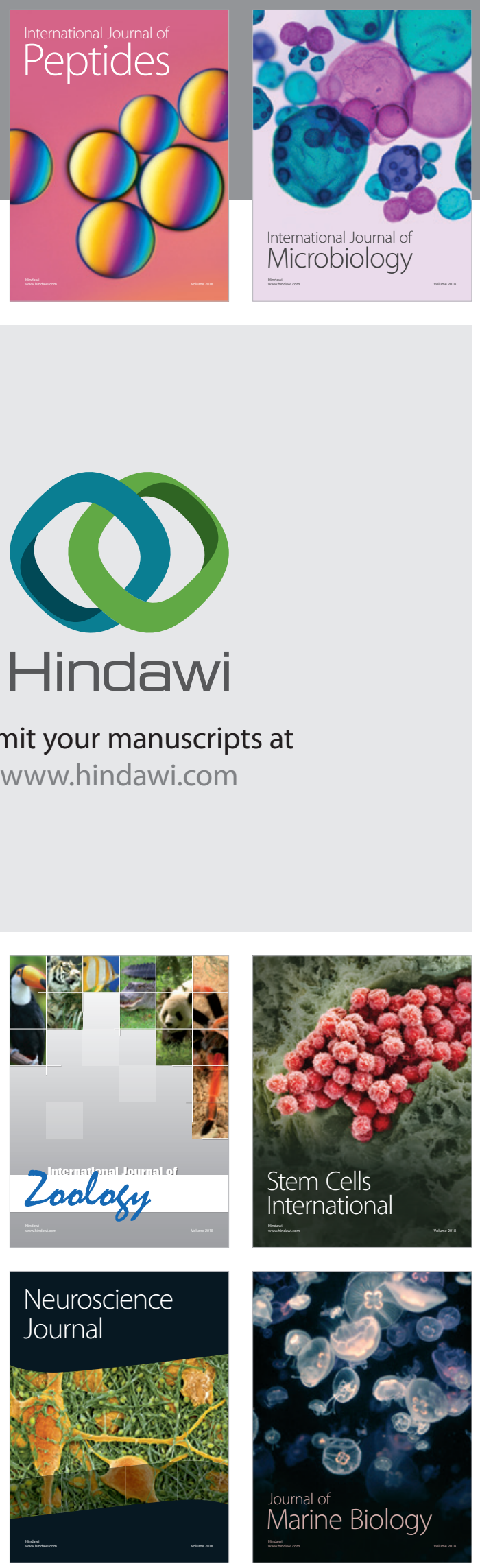
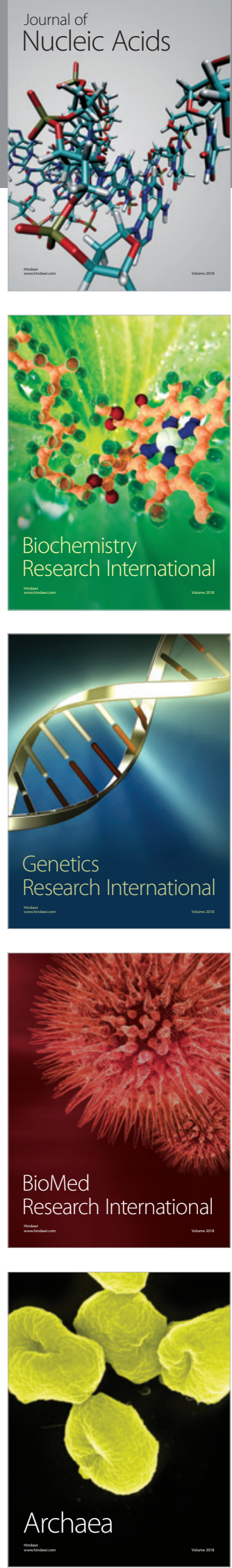